Available online at https://jurnal.stmikroyal.ac.id/index.php/jurdimas

\title{
PENDAMPINGAN PENGELOLAAN SAMPAH TERPADU BERBASIS MASYARAKAT DENGAN KONSEP 3R DI DESA SUKALUYU
}

\author{
Lia Natalia ${ }^{1}$, Hany Wihardja ${ }^{1^{*}}$, Paramitha Wirdani Ningsih ${ }^{2}$ \\ ${ }^{1}$ Program Studi Ilmu Keperawatan, Sekolah Tinggi Ilmu Kesehatan Sint Carolus \\ ${ }^{2}$ Program Studi Ilmu Gizi, Sekolah Tinggi Ilmu Kesehatan Sint Carolus \\ email: *hanywihardja01@gmail.com
}

\begin{abstract}
Reuse, Reduce and Recycle (3R) is the behavior of waste management into a valuable material that can increase the economic benefits of the community and reduce environmental damage affecting global warming. This behavior is often used as a solution to improve the environment that has waste management problems. The purpose of this paper is to identify strategies for optimizing Community Based Independent Waste Management with the 3 R Concept (Reuse, Reduce, Recycle) in Sukaluyu Village, Karawang. This strategy is planned to be able to explore community participation that is bottom-up, starting from the identification of problems and needs of the community, socialization of the concept of $3 \mathrm{R}$ in the household so that people can feel the benefits economically and preserve the environment.The implementation method consists of surveys, hearings, focus group discussions, training, and waste sorting self-practices. This activity is expected to not only improve the environmental quality of the Sukaluyu Village community, but also can change the perceptions and behavior of the community and local stakeholders regarding waste reduction and management. The most important conclusion of this community services is the emphasis on awareness and high involvement motivation of the community in waste management to create culture in the community.
\end{abstract}

Keywords: community participation; reuse reduce recycle; waste management

\begin{abstract}
Abstrak: Reuse, Reduce dan Recycle (3R) adalah perilaku pengelolaan sampah menjadi bahan bernilai yang dapat meningkatkan manfaat ekonomis masyarakat dan mengurangi kerusakan lingkungan yang berdampak terhadap pemanasan global. Konsep $3 \mathrm{R}$ ini sering dijadikan solusi untuk memperbaiki lingkungan yang memiliki masalah dalam pengelolaan sampah. Tujuan dari penulisan ini adalah untuk mengidentifikasi strategi optimalisasi Pengelolaan Sampah Mandiri Berbasis Masyarakat dengan konsep 3 R (Reuse, Reduce, Recycle) di Desa Sukaluyu, Karawang. Strategi ini direncanakan untuk menggali partisipasi masyarakat yang bersifat bottom-up, dimulai dari identifikasi masalah dan kebutuhan masyarakat, sosialisasi konsep 3R di rumah tangga sehingga masyarakat dapat merasakan manfaat secara ekonomis dan menjaga kelestarian lingkungan. Metode pelaksanaan terdiri dari survei, audiensi, focus group discussion, pelatihan, dan praktik mandiri pengolahan-pemilahan sampah. Kegiatan ini diharapkan tidak hanya meningkatkan kualitas lingkungan masyarakat Desa Sukaluyu, namun juga dapat mengubah persepsi dan perilaku masyarakat dan stakeholder setempat terkait pengurangan dan pengelolaan sampah. Kesimpulan penting dari pengabdian ini adalah adanya kesadaran dan motivasi keterlibatan masyarakat yang baik dalam pengelolaan sampah hingga dapat menciptakan budaya di masyarakat.
\end{abstract}

Kata kunci: partisipasi masyarakat; pengelolaan sampah; reuse reduce recycle 
Available online at https://jurnal.stmikroyal.ac.id/index.php/jurdimas

\section{PENDAHULUAN}

Sampah merupakan salah satu permasalahan lingkungan hidup yang memerlukan perhatian serius. Sampah merupakan suatu bahan yang dibuang dari hasil aktivitas manusia maupun proses alam yang belum memiliki nilai ekonomis (Cahyo, Suryaningsih, \& Lestari, 2018). Sampah yang dibuang ke lingkungan dapat menjadi beban dan persoalan bagi lingkungan bila tidak dikelola dengan baik. Berbagai jenis sampah dihasilkan dari aktivitas manusia seperti sampah kaleng, plastik, kertas, sterofoam, kayu, daun, kaca, hasil limbah pabrik dan logam. Secara umum jenis sampah dapat dibedakan menjadi 2 (dua), yaitu sampah organik/basah dan sampah anorganik/kering. Setiap jenis sampah mempunyai cara pengelolaan yang berbeda dan harus tepat berdasarkan jenisnya agar tidak mengakibatkan timbulnya permasalahan di lingkungan masyarakat.

Jumlah penduduk yang meningkat akan berdampak pada peningkatan volume sampah yang dihasilkan oleh masyarakat. Hasil survei yang dilakukan oleh mahasiswa di lingkungan desa Sukaluyu didapatkan bahwa setiap keluarga yang memiliki jumlah anggota keluarga minimal 4 orang dalam satu rumah tangga sebanyak 37\% dari 429 orang total responden. Data yang didapatkan dari Subdirektorat Statistik Lingkungan Hidup menyatakan bahwa setiap orang menghasilkan produksi sampah 0,5-0,8 $\mathrm{kg} /$ hari, sehingga satu rumah tangga yang terdiri dari 4 orang akan menghasilkan 2-3,2 kg/hari. Volume sampah dari 200 jiwa bisa mencapai 100 ton per hari (Subdirektorat Statistik Lingkungan Hidup, 2018). Data ini dapat menggambarkan bahwa sampai tahun 2020 dan seterusnya volume sampah akan terus meningkat.

Peningkatan volume sampah dari tahun ke tahun menjadi alasan yang kuat untuk menjadikan masalah sampah merupakan masalah utama yang harus dicari solusi bersama baik dalam perencanan jangka pendek, menengah dan jangka panjang. Upaya pemerintah untuk menangani sampah telah dilakukan seperti adanya anggaran biaya operasioal serta sarana prasarana pengelolaan sampah. Anggaran tersebut dialokasikan untuk pengelolaan Tempat Pembuangan Akhir (TPA) sampah dan infrastruktur untuk mengelola sampah. Akan tetapi TPA mempunyai keterbatasan penampungan, TPA hanya mampu menampung 40-50\% volume sampah yang dihasilkan dan sisanya berakhir di lahan-lahan kosong atau dibakar. Saat ini $95 \%$ sampah yang dihasilkan dari rumah tangga berakhir di TPA sehingga beban TPA menjadi sangat berat, dan diperlukan lahan yang cukup luas serta fasilitas lingkungan yang relatif mahal (Elamin, Ilmi, Tahrirah, Zarnuzi, Suci, Rahmawati, Dwi, Kusumaardhani, Rohmawati, Bhagaskara, \& Nafisa, 2018). Hal ini tidak menjadi solusi terbaik karena pembebanan akan semakin meningkat dari segi biaya dan sumber daya manusia yang diperlukan untuk mengangkut sampah.

Pengelolaan sampah oleh pemerintah tertuang dalam UU nomor 18 tahun 2008 dimana pemerintah bersama dengan masyarakat wajib melakukan pengelolaan sampah bersama-sama untuk meningkatkan kesehatan masyarakat dan kualitas lingkungan serta menjadikan sampah sebagai sumber daya. Oleh karena itu, permasalahan sampah tidak hanya menjadi tanggung jawab pemerintah akan tetapi menjadi tanggung jawab seluruh lapisan masyarakat. Berbagai upaya masyarakat dalam 
Available online at https://jurnal.stmikroyal.ac.id/index.php/jurdimas

mengelola sampah telah banyak dipelopori oleh tokoh-tokoh masyarakat yang peduli lingkungan. Salah satu upaya yang dilakukan adalah sampah dikelola melalui 3 prinsip yaitu reduce, reuse dan recycle atau pengurangan, penggunaan kembali dan daur ulang sampah (Cahyo, Suryaningsih, \& Lestari, 2018).

Program serupa juga sudah dilakukan di desa Sukaluyu, Kecamatan Teluk Jambe Timur, Karawang, dimana kegiatan sosialisasi mengenai pengelolaan sampah menggunakan prinsip $3 \mathrm{R}$ sudah dilakukan oleh pemerintah $10,5 \%$, LSM 35,7\% dan penduduk asli 51,7\%. Walaupun sosialisasi sudah dilakukan namun $31 \%$ dari warga desa Sukaluyu tidak tahu ada kegiatan tersebut. Hasil survei tersebut juga tercermin dalam pengetahuan dan sikap dari warga desa Sukaluyu yang tidak tahu bagaimana mengelola sampah rumah tangga dan masih mengandalkan TPA sebagai sarana untuk membuang sampah tanpa tahu proses mengelolanya. Data survei diperkuat oleh hasil wawancara yang dilakukan saat kegiatan sosialisasi 3R yaitu warga mengungkapkan masih banyak penduduk asli yang belum mau terlibat dalam pengelolaan sampah dan mempunyai pendapat bahwa pengelolaan sampah merupakan tugas Pemerintah.

(Setiawan, 2018) berdasarkan regulasi UU No.18/2008 tentang Pengelolaan Sampah; Perpres No.97/2017 tentang Kebijakan dan Strategi Nasional Pengelolaan Sampah Rumah Tangga dan Sampah Sejenis sampah Rumah Tangga; Perpres 81 tahun 2012 tentang Pengelo laan Sampah Rumah Tangga dan Sampah Sejenis Sampah Rumah Tangga; dan Permen LH No.13/2012 tentang Pedoman Pelaksanaan Reduce Reuse Recycle menyatakan bahwa perlu adanya pengelolaan sampah rumah tangga yang dilakukan oleh berbagai pihak terutama masyarakat untuk mengurangi kerusakan lingkungan di masa depan. Oleh karena itu, peran serta masyarakat penting dalam pengelolaan sampah secara mandiri melalui konsep solusi 3R untuk dilaksanakan di desa Sukaluyu, Kecamatan Teluk Jambe Timur, Karawang.

\section{METODE}

Pengelolaan sampah mandiri berbasis masyarakat melalui $3 \mathrm{R}$ merupakan pengelolaan sampah yang melibatkan seluruh lapisan masyarakat desa Sukaluyu dengan keterlibatan RT/RW dan tokoh masyarakat. Program ini memiliki konsep dasar swakelola dan swadaya dengan kerangka partisipatif, maka masyarakat dilibatkan aktif pada program optimalisasi pengelolaan sampah ini.

Pelaksanaan kegiatan pengabdian kepada masyarakat ini dilakukan di desa Sukaluyu Kecamatan Teluk Jambe, Karawang pada bulan November 2019 Mei 2019 dengan melibatkan mahasiswa STIK Sint Carolus dengan didampingi oleh dosen pengampu. Metode pelaksanaan terdiri dari pendidikan masyarakat, konsultasi dan advokasi. Langkahlangkah yang dilakukan untuk menjalankan strategi pengelolaan sampah mandiri berbasis masyarakat melalui $3 \mathrm{R}$ yaitu konsultasi yang diawali dengan melakukan survey permasalahan mengenai sampah. Survei ini dilakukan untuk analisis situasi permasalahan sampah yang terjadi di desa Sukaluyu baik di tingkat RT/RW sampai dengan rumah tangga menggunakan kuesioner dan wawancara oleh mahasiswa didampingi oleh dosen. Konsultasi dilakukan untuk mengidentifikasi permasalahan mitra dan kebutuhan masyarakat, Tokoh Masyarakat dan Tokoh Agama yang disinergi- 
Available online at https://jurnal.stmikroyal.ac.id/index.php/jurdimas

kan dengan keilmuan Perguruan Tinggi.

Hasil dari konsultasi ini kemudian disosialisasikan kepada warga yang bersedia untuk ikut andil dalam pengelolaan sampah dan tokoh masyarakat kepala dusun, ketua RT maupun ketua RW melalui audiensi langsung dan focus group discussion. Metode selanjutnya adalah pendidikan masyarakat melalui pendampingan pemilahan sampah dan pembuatan pupuk kompos. Kegiatan pendidikan ini dilakukan dalam 2 tahap yaitu persiapan pembekalan ilmu terkait pengelolaan dan pemilahan sampah, serta tahap kedua adalah melakukan demonstrasi langsung pada mitra.

Metode terakhir mencakup advokasi berupa pendampingan keluarga dalam pemilahan sampah dimulai dari sampah rumah tangga yang sudah dipilah yaitu sampah organik dibuat pupuk kompos dan sampah anorganik dimanfaatkan untuk membuat prakarya seperti tas, hiasan dinding dan lain-lain sehingga dapat bernilai ekonomis. Dampaknya setiap rumah tangga akan menghasilkan jumlah sampah lebih sedikit yang akan dibuang melalui TPA.

\section{PEMBAHASAN}

Kegiatan yang telah dilakukan untuk menjawab strategi optimalisasi pengelolaan sampah mandiri berbasis masyarakat melalui $3 \mathrm{R}$ adalah survei lapangan yang dilakukan di tanggal 2125 November 2018. Kegiatan ini merupakan proses pengumpulan data awal tentang pengetahuan, sikap, perilaku pengolahan sampah dari 429 responden yang mewakili masing-masing keluarga.

Hasil olah data kuesioner didapatkan bahwa $85 \%$ persen masyarakat memiliki pengetahuan yang baik terhadap pengolahan sampah. Ditemukan juga data bahwa sebagian besar warga masih berpersepsi pengelolahan sampah seharusnya dilakukan oleh pemerintah setempat. Hasil ini menjadi dasar bagi tim untuk melakukan strategi untuk mengoptimalkan pengelolaan sampah melalui swakelola dan swadaya dengan kerangka partisipatif.

Hasil survei lainnya didapatkan data bahwa terdapat 93,2\% masyarakat setuju bahwa program pengelolaan sampah dilakukan oleh Pemerintah, serta $50,2 \%$ persen masyarakat berpersepsi seharusnya perbandingan proporsi pengelolaan sampah adalah 100:0 antara pemerintah dan masyarakat. Data ini dapat menjadi bahan pertimbangan bahwa harus dilakukan strategi yang mampu menggali kesadaran dan kemauan masyarakat terhadap pengelolaan sampah rumah tangga. Partisipasi dalam pengelolaan sampah merupakan partisipasi tingkat tinggi karena atas dasar keputusan yang diambil oleh masyarakat setempat (bottom up), dimana keterlibatan masyarakat dalam pengelolaan sampah didasari oleh kesadaran dan determinasi tentang arti keterlibatannya (Haswindy \& Yuliana, 2018).

Rendahnya minat masyarakat dalam pemilahan sampah (34\%) walaupun pengetahuan dan sikap masyarakat dalam kategori baik menjadi hambatan dalam pelaksanaan pengelolaan sampah dengan konsep 3R. Pengetahuan dapat mem-pengaruhi perilaku, hal ini didukung oleh hasil penelitian (Sari, Lestari, \& Awal, 2018) bahwa terdapat peningkatan motivasi untuk menerapkan pengelolaan sampah karena memahami pemanfaatannya yang besar. Persepsi individu dalam Health Belief Model juga berpendapat bahwa perilaku tidak hanya dipengaruhi oleh pengetahuan tetapi seluruh faktor intrapersonal yang mempengaruhi perilaku kesehatan seperti 
Available online at https://jurnal.stmikroyal.ac.id/index.php/jurdimas

usia, jenis kelamin, kepribadian, sosial ekonomi dan edukasi yang didapatkan (Kamal, El-Borgy, \& Wahba, 2017).

Konstruksi teoritis Health Belief Model terdiri dari empat konstruksi utama bahwa perilaku kesehatan dipengaruhi oleh keseriusan yang dirasakan, kerentanan yang dirasakan, manfaat yang dirasakan, dan hambatan yang dirasakan oleh individu (Msengi, 2019). Keseriusan masalah yang dirasakan terkait masalah sampah merupakan urusan pemerintah sehingga masyarakat belum memandang masalah sampah ini serius. Kerentanan yang dirasakan merupakan penilaian individu atas peluangnya untuk terserang penyakit. Dampak penyakit bagi kesehatan belum diketahui sehingga masyarakat belum merasa rentan terhadap penyakit yang bersumber dari pengolahan sampah yang tidak baik (Kementerian Pekerjaan Umum, 2010). Pengelolaan sampah perlu dilakukan bersama dengan masyakat agar penanganaanya dapat optimal. (Setiadi, 2015) menjelaskan bahwa pengolahan sampah terpadu berbasis masyarakat adalah suatu pendekatan pengelolaan sampah yang didasarkan pada kebutuhan dan permintaan masyarakat, direncanakan, dilaksanakan, dikontrol dan dievaluasi bersama masyarakat.

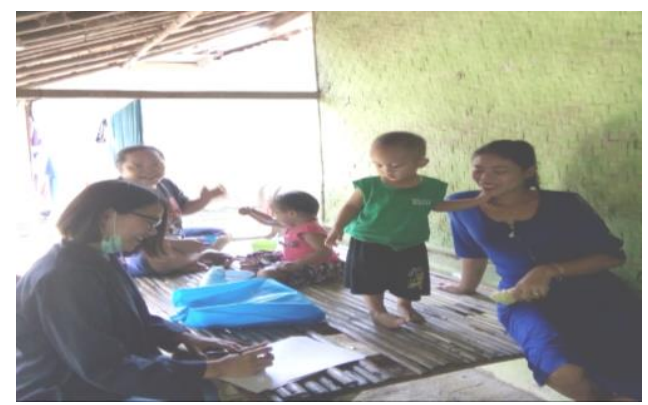

Gambar 1. Kegiatan Survei Awal di Desa Sukaluyu

Pemerintah dan lembaga lainnya berperan sebagai motivator dan fasilitator agar dapat memberikan dorongan agar masyarakat siap memikirkan dan mencari jalan keluar terhadap persoalan sampah yang mereka hadapi.

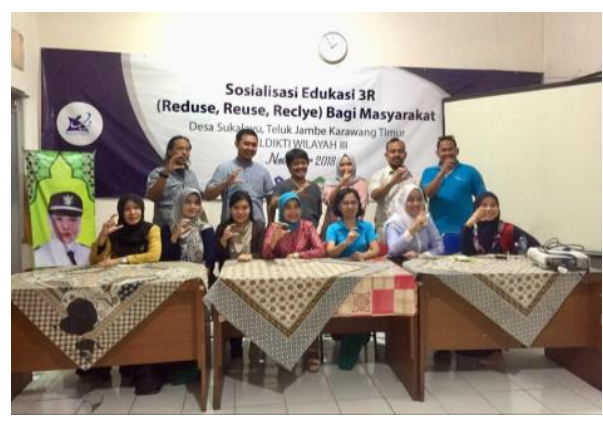

Gambar 2. Kegiatan Identifikasi Permasalahan Mitra dan Sosialisasi Masalah

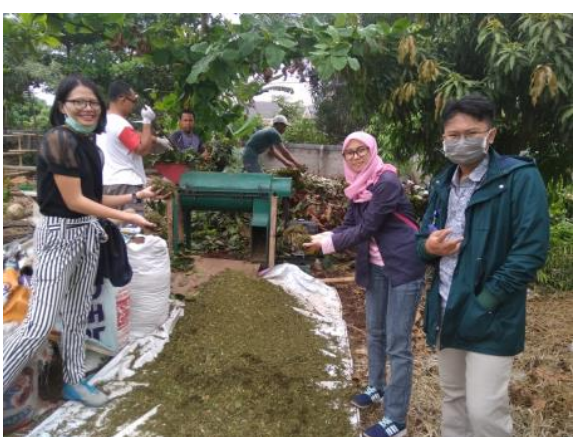

Gambar 3. Kegiatan Persiapan Pemilahan Sampah dan Pembuatan Pupuk Kompos

\section{SIMPULAN}

Dengan menggunakan metode pengelolaan sampah mandiri berbasis masyarakat yaitu metode 3R Reduce, Reuse dan Recycle dimulai dari pemilahan sampah di tingkat rumah tangga dan keterlibatan masyarakat dalam membuat bank sampah sehingga sampah mempunyai nilai ekonomis, dapat bersaing dalam tatanan industry serta menjaga kelestarian lingkungan. Pengelolaan sampah ini diharapkan dapat menyelesaikan permasalahan sampah dengan melibatkan partisipasi aktif seluruh warga masyarakat. 
Available online at https://jurnal.stmikroyal.ac.id/index.php/jurdimas

\section{UCAPAN TERIMA KASIH}

Ucapan terima kasih kami sampaikan kepada LL DIKTI Wilayah III Jakarta dan STIK Sint Carolus yang telah memberikan dukungan finansial terhadap pengabdian ini.

\section{DAFTAR PUSTAKA}

Cahyo, Suryaningsih, \& Lestari. (2018). Analisis strategi pengelolaan sampah terpadu berbasis masyarakat di Kota Semarang. Harmoni, 53(9), 1689-1699.

https://doi.org/10.1017/CBO978110 7415324.004

Elamin, M. Z., Ilmi, K. N., Tahrirah, T., Zarnuzi, Y. A., Suci, Y. C., Rahmawati, D. R., Dwi P., D. M., Kusumaardhani, R., Rohmawati, R. A., Bhagaskara, P. A., \& Nafisa, I. F. (2018). Analisis pengelolaan sampah pada masyarakat Desa Disanah Kecamatan Sreseh Kabupaten Semarang. Jurnal Kesehatan Lingkungan, 10(4), 368. https://doi.org/10.20473/jkl.v10i4.2 018.368-375

Haswindy, S., \& Yuliana, F. (2018). Partisipasi masyarakat dalam pengelolaan sampah pemukiman pada Kecamatan Tungkil Ilir Kabupaten Tanjung Jabung Barat. Jurnal Ilmu Lingkungan, 15(2), 96. https://doi.org/10.14710/jil.15.2.96111.

Kamal, M., El-Borgy, M., \& Wahba, M. (2017). Application of health belief model for hygienic behavior of mothers of hospitalized children in Alexandria. Journal of High Institute of Public Health, 47(1), 13-21. https://doi.org/10.21608/jhiph.2017. 19973

Kementerian Pekerjaan Umum. (2010). Modul Pengolahan Sampah Berbasis 3R. Jakarta: Badan Penelitian dan Pengembangan Pusat Penelitian dan Pengembangan Permukiman. Retrieved from http://litbang.pu.go.id/puskim/sourc e/pdf/Modul\%20Sampah\%203R.pdf

Msengi, I. G. (2019). Development and evaluation of innovative recycling intervention program using the Health Belief Model (HBM). Open Journal of Preventive Medicine, 09(04), 29-41. https://doi.org/10.4236/ojpm.2019.9 4004

Sari, M., Lestari, S. U., \& Awal, R. (2018). Peningkatan ketrampilan mahasiswa dalam pengelolaan sampah organik untuk mewujudkan green campus di Universitas Lancang Kuning. Dinamisia: Jurnal Pengabdian Kepada Masyarakat, 2(2), 193-196. https://doi.org/10.31849/dinamisia.v $2 \mathrm{i} 2.1392$

Setiadi, A. (2015). Studi pengelolaan sampah berbasis komunitas pada kawasan permukiman perkotaan di Yogyakarta. Jurnal Wilayah Dan Lingkungan, 3(April), 27-38.

Setiawan, W. (2018). Citarum harum Kabupaten Karawang. Karawang: Dinas Lingkungan Hidup dan Kebersihan. Retrieved from http://kopertis3.or.id/v5/wpcontent/uploads/Paparan-KadisLHK-Kab-Karawang.pdf

Subdirektorat Statistik Lingkungan Hidup. (2018). Statistik Lingkungan Hidup Indonesia. Jakarta: Badan Pusat Statistik. Retrieved from https://doi.org/3305001. 